\title{
Resonance Raman spectroscopy as an in-situ probe for monitoring catalytic events in a Ru-porphyrin mediated amination reaction
}

\author{
Paolo Zardia , Emma Gallo ${ }^{a}$, Gregory A. Solan ${ }^{\mathrm{b}}$ and Andrew J. Hudson ${ }^{\mathrm{b}^{*}}$ \\ a Dipartimento di Chimica, Università degli Studi di Milano, Via C. Golgi 19, I-20133 Milan, \\ Italy.
}

${ }^{\mathrm{b}}$ Department of Chemistry, University of Leicester, Leicester, LE1 7RH, United Kingdom.

\begin{abstract}
:
Resonance Raman microspectroscopy has been widely used to study the structure and dynamics of porphyrins and metal complexes containing the porphyrin ligand. Here, we have demonstrated that the same technique can be adapted to examine the mechanism of a homogeneously-catalysed reaction mediated by a transition-metal-porphyrin complex. Previously it has been challenging to study this type of reaction using in situ spectroscopic monitoring due to the low stability of the reaction intermediates and elevated-temperature conditions. We have made a straightforward modification to the sample stage on a microscope for time-lapsed Raman microspectroscopy from reaction mixtures in these media. The allylic amination of unsaturated hydrocarbons by aryl azides, which can be catalysed by a rutheniumporphyrin complex, has been used as an illustrative example of the methodology. The mechanism of this particular reaction has been studied previously using density-functional theory and kinetic approaches. The Raman measurements support the mechanism proposed in the earlier publications by providing the first experimental verification of a precursor reaction complex between the aryl azide and the ruthenium metal ion, and evidence for the formation of a mono-imido intermediate complex under conditions of high concentration of the reactant olefin.
\end{abstract}

*Correspondence to: Dr. Andrew J. Hudson, E-mail: andrew.hudson@leicester.ac.uk. 


\section{Introduction}

In situ spectroscopic methods are a useful tool to reveal mechanisms of chemical transformations and the identity of reaction intermediates. Of these methods, Raman spectroscopy can be particularly valuable in obtaining structural and electronic information via the determination of frequencies for vibrations of species present in the reaction mixture. Raman approaches have the advantage over infra-red spectroscopy in that the symmetric vibrational modes of molecules can be observed. A significant disadvantage though is that the intensity of Raman-scattered light is usually weak. In resonance Raman spectroscopy, a monochromatic laser is used which is resonant with excited-electronic states of the reactants, intermediates and/or products. This leads to considerable enhancement of Raman cross sections by a factor of $10^{3}$ to $10^{5},{ }^{1}$ and has enabled the real-time monitoring of fundamental chemical processes by Raman spectroscopy with nanosecond resolution. ${ }^{2-5}$ Continuous-wave lasers have been used in place of pulsed-laser systems to investigate chemical transformations in more complex environments. For example, the prosthetic group in heme proteins is an iron complex, containing the metal in either ferrous or ferric oxidation states, and the ligand protoporphyrin IX. The Raman frequencies of the porphyrin ligand are a sensitive probe of the redox state and the presence of other small molecules bound to the metal centre, ${ }^{6-8}$ and can be used to monitor changes in the state of heme proteins in vivo. ${ }^{9-11} \mathrm{We}$ are interested in using the same approach as an in-situ probe to monitor the evolving states of a homogeneous catalyst in reactions under working conditions (e.g., elevated temperature and/or pressure). There have been limited attempts to develop such in situ techniques suitable to monitor homogeneously-catalysed reactions, however, recently an experimental apparatus was reported for combined UV-Visible absorption, infra red and (non-resonance) Raman spectroscopy using fibre-optic probes but the application of resonance Raman spectroscopy was not explored. ${ }^{12}$

Homogeneous catalysts, based on well-defined transition-metal complexes, are assuming an ever-increasing importance in the production of both commodity and fine chemicals. ${ }^{13,14}$ Many of these complexes have absorption bands in the visible region of the electromagnetic spectrum and the frequencies of the Raman transitions will be affected by the redox state of the centralmetal ion and the coordinative bonding of reactants, intermediates and/or product molecules to the metal centre. Detailed assignment of resonance Raman spectra in ruthenium metal complexes has been given in the literature for ligands containing pyrrole (porphyrin), ${ }^{15}$ pyrazine, ${ }^{16,17}$ pyridine, ${ }^{16,18}$ and pyrimidine ${ }^{17}$ groups, and this earlier work will assist in the analysis of in situ experimental spectra obtained during catalytic reactions involving complexes containing the ruthenium metal ion.

An example of particular interest is the allylic amination of cyclohexene by aryl azides using $\mathrm{Ru}^{\mathrm{II}}$ (TPP)CO (TPP is the dianion of 5,10,15,20-tetraphenylporphyrin) as the catalyst, which 
operates efficiently in refluxing benzene. ${ }^{19}$ Such a transformation is representative of a broad class of homogeneously-catalysed reactions (viz. metal-catalysed nitrene transfer) that are currently receiving considerable attention as a strategy for preparing desirable nitrogencontaining organic compounds from hydrocarbons. ${ }^{20-36}$ Notably the mechanism for this specific amination reaction has been the subject of both a kinetic ${ }^{37}$ and a theoretical investigation ${ }^{38}$ with the former indicating at least two independent catalytic cycles that depend on the ratio of substrate to aryl azide (see Figure 1). At high cyclohexene concentration the active species was considered to be the mono-imido species $\mathbf{B}$ which is highly reactive and would be immediately trapped by a substrate molecule giving the aminated product $\mathbf{E}$ whilst re-generating the starting catalyst $\mathbf{A}, \mathrm{Ru}(\mathrm{TPP}) \mathrm{CO}$. At low cyclohexene concentration, $\mathbf{B}$ undergoes a further reaction with the aryl azide giving, via an unstable intermediate $\mathbf{C}$, the bis-imido complex $\mathbf{D}$ which is now the active species in allylic amination. ${ }^{37}$ Complex $\mathbf{D}$ is stable and can be isolated from the reaction of $\mathbf{A}$ with 3,5-bis(trifluoromethyl)phenyl azide; however, the isolation of bis-imido complexes from aryl azides bearing other electron-withdrawing groups was less successful, and the formation of bis-imido complexes from aryl azides bearing electron-donating groups has never been observed. ${ }^{37}$ In the presence of these other aryl azides, the catalytic cycle was assumed to be restricted to the example involving the mono-imido intermediate $\mathbf{B}$ due the poor stability of imido derivatives. Direct experimental observation of the mono-imido complex B has not been made before. Further support for the proposed mechanism has been obtained using densityfunctional theory ${ }^{38}$, while isolable complexes of the type $\mathbf{A}$ and $\mathbf{D}$ have been structurally characterised. ${ }^{19,39}$

In this article, we will explore the potential of resonance Raman spectroscopy as a tool to investigate the proposed mechanistic steps for the homogeneously-catalysed reaction shown in Figure 1 at different cyclohexene concentrations. It is envisaged that monitoring the timedependent shifts in the vibrational modes of the porphyrin skeleton present in the various ruthenium-porphyrin complexes will shed further light on the identity for the intermediate states of the catalyst. Furthermore, we report for the first time a compact piece of apparatus that has been developed for a high temperature application that can be easily transferred to and from a glove box. 


\section{Experimental Methods}

Amination of an unsaturated hydrocarbon by an aryl azide was catalysed by the ruthenium complex A, Ru ${ }^{\mathrm{II}}(\mathrm{TPP}) \mathrm{CO}$. The reaction was studied using low and high concentrations of the olefin. The solvents, benzene and cyclohexene, used in these experiments were distilled over sodium and stored under nitrogen. Compound $\mathbf{A}$ was synthesised as described elsewhere. ${ }^{40}$ Low concentration of olefin. $1.85 \mathrm{mg}\left(2.5 \times 10^{-3} \mathrm{mmol}\right)$ of A was dissolved in a mixture of benzene $(10 \mathrm{ml})$ and cyclohexene $(114 \mu \mathrm{L}, 1.1 \mathrm{mmol}) .3,5$-bis(Trifluoromethyl)phenyl azide (58 $\mathrm{mg}, 2.3 \times 10^{-1} \mathrm{mmol}$ ) was added under a nitrogen atmosphere, at room temperature, in a glove box.

High concentration of olefin. $1.85 \mathrm{mg}\left(2.5 \times 10^{-3} \mathrm{mmol}\right)$ of $\mathbf{A}$ was dissolved in pure cyclohexene (10 ml). 3,5-bis(Trifluoromethyl)phenyl azide (13 mg, 5.0 $\left.\times 10^{-2} \mathrm{mmol}\right)$ was added under a nitrogen atmosphere, at room temperature, in a glove box.

It should be noted that in the first experiment a higher azide concentration was used to favour the formation of imido species.

Reaction chamber. For both experiments, $0.5 \mathrm{ml}$ of the reaction mixture was transferred to a custom-designed aluminium chamber, which was closed, under a nitrogen atmosphere in a glove box. The reaction chamber provided an air-tight seal for the reaction mixtures, and enabled homogeneous-catalysed reactions in solvents such as benzene to be monitored at elevated temperature using Raman microspectroscopy. The compact design has not been reported previously. The chamber could be separated into two main parts (1 and 2; see Figure 2 I). The first part comprised a well (1) with an internal volume of approximately $1 \mathrm{ml}$ into which one of the reaction mixtures was placed. A thread on the exterior-cylindrical surface (3) enabled the well to be closed, under a nitrogen atmosphere in a glove box, by attaching a collar (2) with an internal thread (4). A viton o-ring (5) was located in a groove machined around the perimeter of the well, and a cover glass (\#1.5, 12 mm-diameter; 6 ) was placed above the o-ring. When the well was tightened onto the collar (Figure 2 II), a seal was obtained between the well and the cover glass. The chamber was inverted to place the reaction mixture in contact with the cover glass (Figure 2 III), and remained sealed in this orientation on heating to $70{ }^{\circ} \mathrm{C}$.

Raman microspectroscopy. Raman spectra were recorded from mixtures inside the air-tight chamber on a homebuilt-inverted microscope; described previously. ${ }^{11}$ The sample stage consisted of an aluminium plate with a kapton-insulated flexible heater bonded onto the lower surface; the temperature of the aluminium plate was monitored by a PT100 resistancetemperature device and regulated at $70{ }^{\circ} \mathrm{C}$. The sample stage was isolated from the body of the microscope by a $1 \mathrm{~cm}$-thick delrin plate. The sample chamber was placed onto the stage such that the cover glass was aligned with a circular opening in both the aluminium and delrin plates. 
An oil-immersion, infinity-corrected, objective lens (1.25 NA) on the microscope was brought into contact with the exterior surface of the cover glass (see Figure 2 III) through the opening in the sample stage. The back aperture of the objective lens was overfilled with the $405 \mathrm{~nm}$-beam (Qioptiq, iFLEX; output linewidth reduced by an etalon to $1 \mathrm{~cm}^{-1}$; approximately $1 \mathrm{~mW}$ ) of a collimated continuous-wave laser. Dichroic mirrors were used to couple the laser light into the imaging optical path and separate the Raman-scattered wavelengths collected by the objective lens from the laser wavelength. Spatial filtering of the Raman scattered light was accomplished by focusing, using a $160 \mathrm{~mm}$ achromatic lens, onto a $150 \mu \mathrm{m}$ pinhole in the confocal image plane. The spatially-filtered light was re-collimated with a second achromatic lens of $160 \mathrm{~mm}$, and then focussed by a $50 \mathrm{~mm}$ achromatic lens onto the $100 \mu \mathrm{m}$-width entrance slits of a spectrograph with a $0.500 \mathrm{~m}$ imaging triple grating monochromator (Acton Research Corporation, Spectra Pro 2500i; 1800 lines/mm grating; $500 \mathrm{~nm}$ blaze wavelength). The detector was a $-80{ }^{\circ} \mathrm{C}$ cooled, back-illuminated, charge-coupled device (Princeton Instruments, Pixis 100B). Spectral data points were measured in increments of $0.018 \mathrm{~nm}$. The optical resolution of the spectroscopic system was $2 \mathrm{~cm}^{-1}$, and the precision for a wavenumber measurement was $0.5 \mathrm{~cm}^{-1}$. The signal-to-noise ratio at the peak position of the $v_{4}$ band of the Ru-porphyrin complex was typically around 40.

Reference solutions. Aniline-coordinated ruthenium complex. Compound A (5.0 mg, $6.7 \times 10^{-3}$ mmol) was suspended in benzene $(5 \mathrm{ml})$ under a nitrogen atmosphere, at room temperature, in a glove box, and an excess of 3,5-bis(trifluoromethyl)aniline (F; $4.2 \mu 1,2.7 \times 10^{-2} \mathrm{mmol}$ ) was added. The mixture was stirred until it became a red solution. Compound $\mathbf{F}$ was synthesised using a previously reported procedure..$^{41}$

Allylic amine-coordinated ruthenium complex. The allylic amine product $\mathbf{E}, \mathrm{C}_{6} \mathrm{H}_{9} \mathrm{NHAr}$ ( $\mathrm{Ar}$ is 3,5-bis(trifluoromethyl)phenyl), was synthesised using a literature procedure ${ }^{37}$ and a solution of E $\left(7.7 \mathrm{mg}, 2.5 \times 10^{-2} \mathrm{mmol}\right)$ was prepared in benzene $(5 \mathrm{ml})$. Compound $\mathbf{A}\left(3.7 \mathrm{mg}, 5.0 \times 10^{-2}\right.$ mmol) was added to the solution.

Mixture of azide reagent and ruthenium-porphyrin catalyst. Compound A (5.0 mg, $6.7 \times 10^{-3}$ mmol) was suspended in benzene $(2 \mathrm{ml})$ under a nitrogen atmosphere, at room temperature, in a

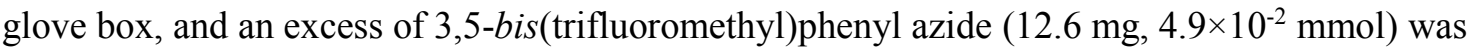
added. A slight colour change from orange/red to red/brown was observed.

Further reference spectra were recorded for the stable complexes $\mathbf{A}, \mathrm{Ru}^{\mathrm{II}}(\mathrm{TPP}) \mathrm{CO}$, and $\mathbf{D}$, $\mathrm{Ru}^{\mathrm{VI}}(\mathrm{TPP})(\mathrm{NAr})_{2}$ (synthesis described elsewhere $\left.{ }^{19}\right)$, and the pure allylic amine $\mathbf{E}$. All measurements were made in benzene solutions, at an approximate concentration of $1 \mathrm{mM}$. 


\section{Results}

\section{Resonance Raman spectroscopy of ruthenium complexes}

Raman spectra, between 450 and $1750 \mathrm{~cm}^{-1}$, of ruthenium complexes with 5,10,15,20tetraphenyl porphyrin (TPP) were obtained using a laser-excitation wavelength of $405 \mathrm{~nm}$. This wavelength is resonant with the Soret absorption band of the ligand. For example, the absorption maximum for the starting catalyst $\mathbf{A}, \mathrm{Ru}^{\mathrm{II}}(\mathrm{TPP}) \mathrm{CO}$, is $418 \mathrm{~nm}$. The resonance Raman spectra for pure samples of $\mathbf{A}$ and the intermediate bis-imido complex $\mathbf{D}, \mathrm{Ru}^{\mathrm{VI}}(\mathrm{TPP})(\mathrm{NAr})_{2}$, are illustrated in Figure 3.

The spectra for both ruthenium complexes in Figure 3 contain two strong vibrational bands derived from the symmetric ring modes of the porphyrin ligand, $v_{4}$ and $v_{2}$. The assignment of the spectra in Figure 3 is consistent with that reported by Spiro and co-workers. ${ }^{15}$ The $v_{4}$ band corresponds to the pyrrole half-ring symmetric stretching vibration and is strongly influenced by the extent of $\pi$-backbonding from the metal $d$ orbitals to the porphyrin $\pi^{*}$ orbital, where an increase in backbonding decreases the frequency of the $v_{4}$ band. Consequently, both the electron density on ruthenium and the nature of any bond formed by the metal to additional ligands in axial positions has an effect on the position of the $v_{4}$ band. The centre wavelength of $v_{4}$ for the 5-coordinate complex $\mathbf{A}$ is $1353 \mathrm{~cm}^{-1}$. A significant shift in the position of $v_{4}$ to $1357 \mathrm{~cm}^{-1}$ is observed for complex $\mathbf{D}$ due to the higher oxidation state of the metal centre. The centre position of the $v_{2}$ band for $\mathbf{A}$ is $1540 \mathrm{~cm}^{-1}$ and this band shifts to $1545 \mathrm{~cm}^{-1}$ for $\mathbf{D}$. Weak vibrational bands are observed in the spectra for the symmetric $v_{3}$ and the asymmetric $v_{12}$ and $v_{13}$ ring modes of the porphyrin ligand. A strong band for the stretching mode between the meso-C and phenyl groups is observed at $1227 \mathrm{~cm}^{-1}$ for $\mathbf{A}$ and $1233 \mathrm{~cm}^{-1}$ for $\mathbf{D}$. Additional weaker bands are observed for the stretching vibration between the $\beta-\mathrm{C}$ and $\mathrm{H}$ atoms and the phenyl ring modes in the TPP ligand but a displacement in the position of these bands following a change in the oxidation or coordination state of the ruthenium centre was not observed.

There are two bands observed in the spectra shown in Figure 3, which are not derived from the TPP ligand. The Ru-CO stretching band is observed at $525 \mathrm{~cm}^{-1}$ in compound $\mathbf{A}, \mathrm{Ru}^{\mathrm{II}}(\mathrm{TPP}) \mathrm{CO}$. The $v_{12}$ in-plane ring deformation mode for the 1,3,5-trisubstituted phenyl ligand, Ar, is observed at $1010 \mathrm{~cm}^{-1}$ in compound $\mathbf{D}, \mathrm{Ru}^{\mathrm{VI}}(\mathrm{TPP})(\mathrm{NAr})_{2}$. The $v_{12}$ mode is Raman inactive for the unsubstituted phenyl group in TPP and benzene solvent.

The $v_{2}$ ring-stretching mode for benzene is observed at $991 \mathrm{~cm}^{-1}$, along with weaker bands at $605 \mathrm{~cm}^{-1}$ ( $v_{18}$, ring deformation), $847 \& 1176 \mathrm{~cm}^{-1}$ ( $v_{11} \& v_{17} \mathrm{C}-\mathrm{H}$ bending), and $1584 \& 1604$ $\mathrm{cm}^{-1}$ ( $v_{16}$ ring stretching). 
The resonance Raman spectra for $\mathbf{A}, \mathrm{Ru}^{\mathrm{II}}(\mathrm{TPP}) \mathrm{CO}$, in the presence of excess 3,5bis(trifluoromethyl)phenyl azide, $\mathrm{ArN}_{3}$, is shown in Figure 4. There is evidence in this spectrum for the formation of a complex which would be a precursor for the allylic amination reaction illustrated in Figure 1. Tentatively, it could be suggested that the identity of the complex formed is $\mathrm{Ru}^{\mathrm{II}}(\mathrm{TPP})\left(\mathrm{ArN}_{3}\right) \mathrm{CO}$; however, this species has been predicted to be weakly bound. ${ }^{38}$ The most significant evidence for the formation of a precursor complex is the shift in the $v(\mathrm{Ru}-\mathrm{CO})$ stretching band from $525 \mathrm{~cm}^{-1}$ in the 5-coordinate complex A to $497 \mathrm{~cm}^{-1}$ following the occupation of the $6^{\text {th }}$ coordination position, trans to the CO ligand, on the ruthenium-metal ion. The frequency of the $v(\mathrm{Ru}-\mathrm{CO})$ band is affected by back-bonding from the Ru d orbitals to the $\mathrm{CO} \pi^{*}$ orbital. In this case, the reduction in backbonding on ligand binding decreases the bond order of the Ru-CO (metal-to-ligand) bond (whilst increasing the bond order of the C-O bond), leading to a decrease the frequency of the $v(\mathrm{Ru}-\mathrm{CO})$ band. The CO ligand has a high affinity for the metal $\mathrm{d}$ electrons and the degree of back bonding to the $\mathrm{CO} \pi^{*}$ orbital is very significant in the complex $\mathrm{Ru}^{\mathrm{II}}(\mathrm{TPP}) \mathrm{CO}$. The prediction of weak binding between $\mathrm{ArN}_{3}$ and the rutheniummetal ion does not entirely preclude the possibility that $\mathrm{ArN}_{3}$ could act as an electronwithdrawing ligand in the $6^{\text {th }}$ coordinate position, which is favoured by the presence of $\mathrm{CF}_{3}$ groups on the aryl moiety; this would cause a significant decrease in the back bonding from $\mathrm{Ru}$ to the $\mathrm{CO} \pi^{*}$ orbital, however, this might be expected to increase the order of the $\mathrm{Ru}-\mathrm{N}$ bond.

It is reported in the literature that the porphyrin ligand in the complexes, $\mathrm{Ru}^{\mathrm{II}}(\mathrm{TPP})(\mathrm{X}) \mathrm{CO}$, could be in competition with the $\mathrm{CO}$ ligand for the metal d electrons, however, the $\mathrm{CO}$ ligand has a much higher affinity for the $\mathrm{d}$ electrons than the porphyrin ligand. ${ }^{15}$ Consequently, there is a relatively small variation in the frequency of the $v_{4}$ band in $\mathrm{Ru}^{\mathrm{II}}(\mathrm{TPP})(\mathrm{X}) \mathrm{CO}$ complexes as back-bonding to the porphyrin ligand is always weak in the presence of an axial $\mathrm{CO}$ ligand; $v_{4}$ has been measured from 1350 to $1358 \mathrm{~cm}^{-1}$ for the various $\mathrm{Ru}^{\mathrm{II}}$ complexes in this work. In addition, the frequency of the $v_{4}$ band in the high oxidation state $\left(\mathrm{Ru}^{\mathrm{VI}}\right)$ complex, $\mathbf{D}$, is not that much different to the values found in the low oxidation state $\left(\mathrm{Ru}^{\mathrm{II}}\right)$ complexes. This means that the oxidation state of the metal can have only a small effect on the degree of back-bonding to the porphyrin ligand in the presence of an axial CO ligand; i.e. the higher electron density on the $\mathrm{Ru}^{\mathrm{II}}$ metal is re-directed to the $\mathrm{CO}$ ligand in preference to the porphyrin ligand. In the complex formed on addition of $\mathrm{ArN}_{3}$ to $\mathrm{Ru}^{\mathrm{II}}(\mathrm{TPP}) \mathrm{CO}$ (see Figure 4), there is a decrease in back-bonding to the $\mathrm{CO} \pi^{*}$ orbital (described above) and a similar decrease in back-bonding to the porphyrin $\pi^{*}$ orbital might also be expected, which would lead to an increase in the $v_{4}$ frequency. The opposite is observed in the experimental data, and a small decrease in the frequency of the $v_{4}$ band from 1353 to $1350 \mathrm{~cm}^{-1}$ was measured. We speculate that the reason for this could be the geometry of the resulting complex. The location of a ligand trans to the $\mathrm{CO}$ results in strong 
overlap between the $\pi$ orbitals across a planar configuration of axial bonds which has a very substantial effect on the back bonding to the $\mathrm{CO} \pi^{*}$ orbital. The ligand in the $6^{\text {th }}$ coordinate axial position cannot have such a direct interaction with the porphyrin ligand which is located in a perpendicular plane. The $6^{\text {th }}$ coordinate ligand removes electron density from the Ru-C bond. Most of this electron density is redistributed to $\pi$-bonding to the azide group, but it seems likely that, in this configuration, there is also some additional back-bonding interaction to the porphyrin $\pi^{*}$ orbital. This causes a small decrease in the frequency of the $v_{4}$ band.

The absence of the aryl $v_{12}$ band in the spectrum shown in Figure 4 could be due to the weak interaction between $\mathrm{ArN}_{3}$ and ruthenium. Vibrational bands will not be observed in the measured spectrum unless the Raman cross-section is enhanced, via an electronic resonance with the excitation laser mediated by the porphyrin ligand. The centre position of the $v_{2}$ and $v\left(\mathrm{C}_{\mathrm{m}}-\mathrm{Ph}\right)$ bands are $1540 \mathrm{~cm}^{-1}$ and $1226 \mathrm{~cm}^{-1}$, respectively; similar to the band positions observed for complex A. The Raman spectrum reported in Figure 4 indicates an interaction between $\mathrm{ArN}_{3}$ and $\mathrm{Ru}(\mathrm{TPP}) \mathrm{CO}$ and, even if it is not possible to definitively identify the nature of the obtained complex, the immediate formation of a bis-imido stable compound $\mathbf{D}$ can be excluded (see below).

A non-resonance Raman spectrum is shown in Figure 5 (black line) for a solution containing the allylic amine $\mathbf{E}, \mathrm{C}_{6} \mathrm{H}_{9} \mathrm{NHAr}$ (the product in the scheme shown in Figure 1). All the bands observed in the spectrum correspond to vibrational modes of the benzene solvent. Addition of $\mathbf{E}$ to $\mathrm{A}, \mathrm{Ru}(\mathrm{TPP}) \mathrm{CO}$ (in equimolar equivalents), results in the appearance of a resonance Raman spectrum, in which the bands are observed again for the aforementioned porphyrin ligand modes $\left(v_{4} 1358 \mathrm{~cm}^{-1}, v_{2} 1545 \mathrm{~cm}^{-1}\right.$ and $\left.v\left(\mathrm{C}_{\mathrm{m}}-\mathrm{Ph}\right) 1231 \mathrm{~cm}^{-1}\right)$ together with the Ru-CO stretching mode and the aryl $v_{12}$ mode. The appearance of the aryl $v_{12}$ band suggests that $\mathbf{E}$ is bound to the $6^{\text {th }}$ coordination position on the ruthenium metal centre to give $\mathrm{Ru}^{\mathrm{II}}(\mathrm{TPP})(\mathbf{E}) \mathrm{CO}$ in the solution. The resulting complex has a strong fluorescence, with an emission peak maximum $>440 \mathrm{~nm}$. The spectra shown in Figure 5 demonstrate clearly that the aryl $v_{12}$ band is enhanced by an electronic resonance, mediated by the porphyrin ligand, following the binding of the allylic amine $\mathbf{E}$ to ruthenium; with the Raman scattering cross section correspondingly lower for the free allylic amine in solution. As described above, the $\mathrm{CO}$ has a high affinity for the delectrons and backbonding to the porphyrin ligand is weak in complexes containing an axial CO ligand. The effect of binding of $\mathbf{E}$ to the $6^{\text {th }}$ coordination position appears to have resulted in fact in a slight decrease in backbonding to the porphyrin ligand. The new position of the $v_{4}$ band, at a relatively high wavenumber position of $1358 \mathrm{~cm}^{-1}$, is very similar to that found in the $\mathrm{Ru}^{\mathrm{VI}}$ complex, $\mathbf{D}$, illustrating the point that the larger $\mathrm{d}$ electron density in the $\mathrm{Ru}^{\mathrm{II}}$ complex is mostly redirected to the Ru-CO bond. The secondary amine has exerted little effect on back-bonding to 
the CO ligand (or any shift in this band at the much lower frequency of $\sim 520 \mathrm{~cm}^{-1}$, compared to the $v_{4}$ band at $\sim 1350 \mathrm{~cm}^{-1}$, cannot be discerned).

The resonance Raman spectrum obtained following the addition of $\mathbf{F}, \mathrm{ArNH}_{2}$, to complex $\mathbf{A}$ is shown at the top of Figure 5. Compound $\mathbf{F}$ is a by-product of the decomposition of bis(trifluoromethyl)phenyl azide, and the presence of $\mathrm{Ru}^{\mathrm{II}}(\mathrm{TPP})(\mathbf{F}) \mathrm{CO}$ at the conclusion of the catalysed amination reaction is considered likely. ${ }^{37}$ The fluorescence of $\mathrm{Ru}^{\mathrm{II}}(\mathrm{TPP})(\mathbf{F}) \mathrm{CO}$ is considerably lower than $\mathrm{Ru}^{\mathrm{II}}(\mathrm{TPP})(\mathbf{E}) \mathrm{CO}$. The $v_{4}$ band for $\mathrm{Ru} \mathrm{u}^{\mathrm{II}}(\mathrm{TPP})(\mathbf{F}) \mathrm{CO}$ is centred at 1355 $\mathrm{cm}^{-1}$ which is the expected position for $v_{4}$ in a low oxidation-state complex (equivalent to complex A in Figure 3) and contrasts with the unusually high value measured for $\mathrm{Ru}^{\mathrm{II}}(\mathrm{TPP})(\mathbf{E}) \mathrm{CO}$. The wavenumber positions of the other porphyrin modes for $\mathrm{Ru}^{\mathrm{II}}(\mathrm{TPP})(\mathbf{F}) \mathrm{CO}$ are similar to those for $\mathrm{Ru} \mathrm{u}^{\mathrm{II}}(\mathrm{TPP})(\mathbf{E}) \mathrm{CO}: v_{2} 1545 \mathrm{~cm}^{-1}$ and $v\left(\mathrm{C}_{\mathrm{m}}-\mathrm{Ph}\right) 1230 \mathrm{~cm}^{-1}$. The aryl $v_{12}$ mode is clearly present in the spectrum of $\mathrm{Ru}^{\mathrm{II}}(\mathrm{TPP})(\mathbf{F}) \mathrm{CO}$. The $\mathrm{Ru}-\mathrm{CO}$ stretching mode has not been resolved clearly though; however, the formation of bis-substituted complex in which the CO ligand is replaced by a second aniline molecule is not likely. IR measurements of the purified compound, isolated from benzene solutions, indicate the presence of the $\mathrm{C}-\mathrm{O}$ stretching band at around $1900 \mathrm{~cm}^{-1} \cdot{ }^{37}$ In this example, it is proposed that the Ru-CO stretching mode becomes unresolved following the binding of the primary amine $\mathbf{F}$ to the $6^{\text {th }}$ coordination position on the ruthenium metal ion. Evidence that the $v(\mathrm{Ru}-\mathrm{CO})$ band is not as well resolved following the binding of certain ligands to the $6^{\text {th }}$ coordination position is supported by the data described above for the precursor complex formed between the starting catalyst $\mathbf{A}$ and $\operatorname{ArN}_{3}$. The resolution of the $v(\mathrm{Ru}-\mathrm{CO})$ band would be more challenging for $\mathrm{Ru}^{\mathrm{II}}(\mathrm{TPP})(\mathbf{F}) \mathrm{CO}$, compared with the complex formed between $\mathbf{A}$ and $\mathrm{ArN}_{3}$, as a result of the increase in fluorescence background in the measured spectrum. The C-O stretching band at around $1900 \mathrm{~cm}^{-}$

${ }^{1}$ is weak in Raman spectra, relative to IR measurements, and it was not resolved above the fluorescence background when the spectral range was extended to higher wavenumbers.

A low power of the $405 \mathrm{~nm}$ laser was used in these experiments and there was no evidence of laser photolysis leading to a reduction in the intensity of the $\mathrm{Ru}-\mathrm{CO}$ band in the resonance Raman spectra.

\section{$R u^{I I}(T P P) C O$-catalysed amination reaction of unsaturated hydrocarbons by aryl azides}

The amination of an unsaturated hydrocarbon by an aryl azide, catalysed by the ruthenium porphyrin complex $\mathbf{A}, \mathrm{Ru}^{\mathrm{II}}(\mathrm{TPP}) \mathrm{CO}$, was studied under the condition of a low concentration of olefin (1 part cyclohexene to 100 parts benzene). Resonance Raman spectra of the reaction mixture recorded after 0, 8, 20 31, 34.5 and 36 minutes are shown in Figure 6. 
The Raman band corresponding to the Ru-CO stretching mode is observed throughout the course of the reaction. The aryl $v_{12}$ band increases in intensity steadily between 0 and 36 minutes, which implies that either the main product $\mathbf{E}$ or a by-product, such as $\mathbf{F}$, containing the Ar group donated by the aryl azide, remains bonded to the ruthenium catalyst at the conclusion of the reaction. The shift in the position of the $v_{4}$ band during the course of the reaction, at low olefin concentration, is shown in more detail in Figure 7. Although the shift in the centre position of the band, from $1354 \mathrm{~cm}^{-1}$ to $1356 \mathrm{~cm}^{-1}$, is relatively small, the peak maximum can be identified precisely in the sequence of spectra as a result of the low noise level leading to signal fluctuations across single pixels only (an error bar of \pm 1 pixel is shown in Figure 7). No observable shift is observed in the $v_{2}$ band (centre wavenumber, $1543 \mathrm{~cm}^{-1}$ ). Although there is some evidence of broadening of the $v\left(\mathrm{C}_{\mathrm{m}}-\mathrm{Ph}\right)$ band, this feature also remains at the same centre position of $1229 \mathrm{~cm}^{-1}$. The fluorescence background increases significantly during the course of the reaction. The final spectrum in Figure 6 should be compared with that reported in Figure 5 for a mixture of the starting catalyst $\mathrm{Ru}^{\mathrm{II}}(\mathrm{TPP}) \mathrm{CO}, \mathbf{A}$, and compound $\mathbf{E}$. It was noted above, unexpectedly, that the position of the $v_{4}$ was similar for $\mathbf{E}$ and the $\mathrm{Ru}^{\mathrm{VI}}$ complex $\mathbf{D}$.

The catalytic amination reaction was subsequently studied under the condition of a high concentration of olefin (pure cyclohexene; absence of benzene solvent). Resonance Raman spectra of the reaction mixture, recorded at frequent intervals between 0 and 122 minutes, are shown in Figure 8 . The $1^{\text {st }}$ and last spectra are also highlighted in the inset across the wavenumber region of the $v(\mathrm{Ru}-\mathrm{CO})$ band; for these highlighted spectra only, the raw data has been background subtracted to remove the broad fluorescence emission underneath the Raman features.

The Raman band corresponding to the Ru-CO stretching mode is observed at a low wavenumber position of $495 \mathrm{~cm}^{-1}$ from the onset of the reaction, similar to that shown in Figure 4 following mixing of $\mathrm{Ru}^{\mathrm{II}}(\mathrm{TPP}) \mathrm{CO}$ with the aryl azide (see inset in Figure 8). The $v(\mathrm{Ru}-\mathrm{CO})$ band is more difficult to resolve during the course of the reaction, however, by subtracting the fluorescence background, a combination of the low and high wavenumber $v(\mathrm{Ru}-\mathrm{CO})$ bands is observed (see inset in Figure 8), corresponding to a mixture of imido complex, $v(\mathrm{Ru}-\mathrm{CO})$ at 495 $\mathrm{cm}^{-1}$, and $\mathrm{Ru}^{\mathrm{II}}$ complexes, $v(\mathrm{Ru}-\mathrm{CO}) \sim 520 \mathrm{~cm}^{-1}$. Once again, the aryl $v_{12}$ band increases in intensity during the course of the catalytic reaction, indicating that a ligand containing the 3,5bis(trifluoromethyl)phenyl substituent remains bound to the ruthenium metal centre as the reaction proceeds. The shift in the position of the $v_{4}$ and $v\left(C_{m}-P h\right)$ bands is shown in more detail in Figure 9. Once again, the overall shift in peak positions is relatively small but the low noise level leads to signal fluctuations across single pixels only (an error bar of \pm 1 pixel is shown in Figure 9). The centre position of the $v_{4}$ band shifts from 1354 to $1358 \mathrm{~cm}^{-1}$ after approx. 27.5 
minutes, and back to $1355 \mathrm{~cm}^{-1}$ after 95 - 108 minutes of the reaction; the centre position of the $v\left(\mathrm{C}_{\mathrm{m}}-\mathrm{Ph}\right)$ band shifts from 1226 to $1231 \mathrm{~cm}^{-1}$ after 12.5 minutes of the reaction. As in the previous example at low olefin concentration, there is no observable shift seen in the $v_{2}$ band (centre wavenumber is $1545 \mathrm{~cm}^{-1}$ ) and the fluorescence increases during the course of the reaction at high olefin concentration. The latter result is consistent with the eventual coordination of the allylic amine product $\mathbf{E}$ to the ruthenium metal centre. At low olefin concentration, there were no further changes in the Raman spectrum after 36 minutes; in contrast, at high concentration of olefin, there were significant changes in the Raman spectrum for up to 122 minutes.

\section{Discussion}

\section{Low concentration of olefin.}

The mechanism of the ruthenium-catalysed amination reaction proposed, ${ }^{37}$ and illustrated in Figure 1, suggests that a bis-imido complex $\mathbf{D}, \mathrm{Ru}^{\mathrm{VI}}(\mathrm{TPP})(\mathrm{NAr})_{2}$, is formed as an intermediate at low olefin concentration. The persistence of the Ru-CO stretching band in the Raman spectra indicates that part of the catalyst is not converted to the bis-imido complex at any stage of the reaction; the most likely explanation is that the reaction is taking place via both cycles shown in Figure 1. The increase in the fluorescence background is consistent with the coordination of the allylic amine product $\mathbf{E}, \mathrm{C}_{6} \mathrm{H}_{9} \mathrm{NHAr}$, to the $6^{\text {th }}$ position on the ruthenium metal centre, in either unreacted or recovered complex $\mathbf{A}$, to give $\mathrm{Ru}^{\mathrm{II}}(\mathrm{TPP}) \mathrm{COE}$.

The exact identification of intermediates or products from the positions of various bands $\left(v_{2}, v_{4}\right.$ and $\left.v\left(\mathrm{C}_{\mathrm{m}}-\mathrm{Ph}\right)\right)$ in the Raman spectra cannot be made. These bands are relatively broad in the measured spectra and, in the course of the reaction, must contain unresolved contributions from different species. As noted above, it is suspected that the reaction could be taking place via both cycles shown in Figure 1. The shift in the position of the pyrrole half-ring symmetric-stretching vibraton, $v_{4}$, observed during the catalysed reaction is similar to that observed either following an oxidation state change of the metal centre $\left(\mathrm{Ru}^{\mathrm{II}} \rightarrow \mathrm{Ru}^{\mathrm{VI}}\right)$ or the binding of the allylic amine $\mathbf{E}$ to the $6^{\text {th }}$ coordination position in the ruthenium complex $\left(\mathrm{Ru}^{\mathrm{II}}(\mathrm{TPP}) \mathrm{CO}+\mathrm{E} \rightarrow\right.$ $\left.\mathrm{Ru}^{\mathrm{II}}(\mathrm{TPP}) \mathrm{COE}\right)$. The strong fluorescence is further evidence for the binding of the target product $\mathbf{E}$ to the ruthenium metal centre. Since the by-product $\mathbf{F}$ proposed in reference 37 has been shown to give a complex with low fluorescence intensity on binding to the vacant coordination site in $\mathbf{A}$, it seems likely that the target product $\mathbf{E}$ is dominant in the final mixture. The final spectrum in Figure 7 shows a $v(\mathrm{Ru}-\mathrm{CO})$ band (following fluorescence background subtraction) which could suggest a mixture of $\mathrm{Ru}^{\mathrm{II}}(\mathrm{TPP}) \mathrm{COE}$ and the starting catalyst $\mathbf{A}$. 


\section{High concentration of olefin.}

The previously proposed mechanism for the ruthenium-catalysed amination reaction, ${ }^{37}$ and illustrated in Figure 1, suggested that a mono-imido complex $\mathbf{B}, \mathrm{Ru}^{\mathrm{IV}}(\mathrm{TPP})(\mathrm{NAr}) \mathrm{CO}$, is formed as an intermediate at high olefin concentration. This is supported by the appearance of the $v(\mathrm{Ru}-$ $\mathrm{CO}$ ) band at a low wavenumber position as a result of the binding of the imido group to the $6^{\text {th }}$ coordination position on ruthenium in a trans geometry with the CO ligand; a similar low wavenumber for the $v(\mathrm{Ru}-\mathrm{CO})$ band was observed for the supposed azide complex. A combination of the low and high wavenumber $v(\mathrm{Ru}-\mathrm{CO})$ bands is observed during the course of the reaction, and it is likely that a mixture of imido complex, at low $v(\mathrm{Ru}-\mathrm{CO})$, and $\mathrm{Ru}^{\mathrm{II}}$ complexes, at high $v(\mathrm{Ru}-\mathrm{CO})$, exist at the conclusion of the reaction. This result supports the proposal of complex $\mathbf{B}$ as a reaction intermediate following the theoretical study published earlier. ${ }^{38}$ This is further substantiated by shifts in the $v_{4}$ and $v\left(\mathrm{C}_{\mathrm{m}}-\mathrm{Ph}\right)$ bands to higher wavenumbers during the initial 27.5 minutes of the reaction consistent with an intermediate, such as the mono-imido complex $\mathbf{B}\left(\mathrm{Ru}^{\mathrm{IV}}\right)$, with a high oxidation state being dominant in the reaction mixture. The subsequent decrease in the wavenumber position for the $v_{4}$ band after $95-$ 108 minutes of the reaction supports the proposed mechanism that reduction of complex $\mathbf{B}$ $\left(\mathrm{Ru}^{\mathrm{IV}}\right)$ takes place to give a final resting state for the catalyst as a $\mathrm{Ru}^{\mathrm{II}}$ complex.

The increase in the fluorescence background during the course of the reaction at high olefin concentration is consistent with the binding of allylic amine product $\mathbf{E}$ to the ruthenium complex to give $\mathrm{Ru}^{\mathrm{II}}(\mathrm{TPP}) \mathrm{COE}$. There are two notable differences though in comparing the results obtained at high and low concentrations of the olefin. In the previous example at low olefin concentration, (i) the $v(\mathrm{Ru}-\mathrm{CO})$ band was resolved clearly at the high wavenumber position, and (ii) the position of the $v_{4}$ band did not shift back to a lower wavenumber at the conclusion of the reaction. In the present example, at high olefin concentration, the initial increase followed by a decrease in the wavenumber position of the $v_{4}$ band is as might have been expected for the proposed reaction mechanism shown in Figure 1; i.e. the $v_{4}$ band shifts to a higher wavenumber position as a consequence of the formation of complex $\mathbf{B}\left(\mathrm{Ru}^{\mathrm{IV}}\right)$ but then returns to a lower wavenumber position as a consequence of the recovery of the $\mathrm{Ru}^{\mathrm{II}}$ oxidation level in the resting state of the catalyst. 


\section{Conclusion}

The resonance Raman spectra recorded during the course of the chemical reaction support the mechanistic proposal for the formation of (i) a precursor complex between the starting catalyst, $\mathrm{Ru}(\mathrm{TPP}) \mathrm{CO}$, and the aryl azide and (ii) a mono-imido intermediate, $\mathrm{Ru}^{\mathrm{IV}}(\mathrm{TPP})(\mathrm{NAr}) \mathrm{CO}$, at high concentrations of olefin. Both of these complexes were proposed earlier on the basis of theoretical studies. The new experimental data also suggests that a mono-imido intermediate could exist transiently only for low concentrations of olefin, where the formation of a bis-imido $\mathrm{Ru}^{\mathrm{VI}}(\mathrm{TPP})(\mathrm{NAr})_{2}$ catalytic active species was already proposed. The resonance Raman spectra have provided a clear indication of the resting state of the metal complex catalyst in solution, with the allylic amine product binding to the $6^{\text {th }}$ coordination position on the metal centre to produce a fluorescent complex.

The same methodology that was used in this work to study the amination of unsaturated hydrocarbons by aryl azides could be used to investigate other homogeneous reactions catalysed by transition-metal complexes. Conditions for resonance Raman spectroscopy would need to be achieved by appropriate selection of the excitation wavelength. In the present example, both redox changes and ligand binding/substitution steps involving the ruthenium-porphyrin catalyst could be determined during the course of reactions by the use of a $405 \mathrm{~nm}$ laser, which is resonant with the Soret absorption band of the porphyrin ligand. For another example, a different wavelength will be required which is resonant with any of the absorption features of the catalyst, which could include d-d transitions of the metal, however, a stronger enhancement of Raman bands is likely from resonance with the absorption features for one of the ligand groups. A relatively straightforward sample chamber has been constructed that can be sealed, containing the reaction mixtures, inside a glove box, and transferred to a heated microscope stage in order to monitor the ensuing reaction in situ by resonance Raman spectroscopy. In the present example, a temperature of $70^{\circ} \mathrm{C}$ was used to achieving refluxing conditions in benzene; any other temperature up to this value could be used but this was the highest accessible temperature for which stable focussing of the confocal Raman microscope could be maintained. 


\section{Figure captions}

Figure 1: Proposed mechanism for the $\mathrm{Ru}^{\mathrm{II}}(\mathrm{TPP}) \mathrm{CO}$-catalysed amination reaction of cyclohexene by aryl azides; adapted from reference 37.

Figure 2: Custom-designed sealed reaction chamber. I. The chamber comprises a well (1) with an internal volume of approx. $1 \mathrm{ml}$ and a cap (2). A male-thread on the well (3) and a femalethread on the collar (4) enables the contents to be sealed, under a nitrogen atmosphere in a glove box, by tightening to bring a viton o-ring (5) in contact with a \#1.5-sized cover glass (6). II. The chamber is inverted placing the reaction mixture in contact with the cover glass. III. Raman microspectroscopy can be performed by positioning the objective lens of an inverted microscope in contact with the cover-glass window.

Figure 3: Resonance Raman spectra of ruthenium complexes. Red - Ru ${ }^{\mathrm{II}}(\mathrm{TPP}) \mathrm{CO}(\mathbf{A})$. Green $\mathrm{Ru}^{\mathrm{VI}}(\mathrm{TPP})(\mathrm{NAr})_{2}(\mathbf{D})$.

Figure 4: Resonance Raman spectra of $\mathrm{Ru}^{\mathrm{II}}(\mathrm{TPP}) \mathrm{CO}(\mathbf{A})$ in the presence of excess $\mathrm{ArN}_{3}$.

Figure 5: Black - Non-resonance Raman spectrum of the allyl amine, $\operatorname{ArNH}\left(\mathrm{C}_{6} \mathrm{H}_{9}\right)(\mathbf{E})$. Red Resonance Raman spectrum recorded from a mixture of $\mathrm{Ru}^{\mathrm{II}}(\mathrm{TPP}) \mathrm{CO}(\mathbf{A})$ and $\mathbf{E}$. Blue Resonance Raman spectrum recorded from a mixture of $\mathbf{A}$ and $\mathrm{ArNH}_{2}(\mathbf{F})$.

Figure 6: Time-lapse resonance Raman spectra of the catalytic reaction mixture under the conditions of low olefin concentration.

Figure 7: The observed shift in the $v_{4}$ band observed by resonance Raman spectra in the catalysed-amination reaction mixture under the conditions of low olefin concentration.

Figure 8: Time-lapse resonance Raman spectra of the catalytic reaction mixture under the conditions of high olefin concentration. Inset - The $v(\mathrm{Ru}-\mathrm{CO})$ band in the first and last spectra (corrected for the fluorescence background).

Figure 9: The observed shift in the $v\left(\mathrm{C}_{\mathrm{m}}-\mathrm{Ph}\right)$ and $v_{4}$ bands observed by resonance Raman spectra in the catalysed-amination reaction mixture under the conditions of high olefin concentration. 

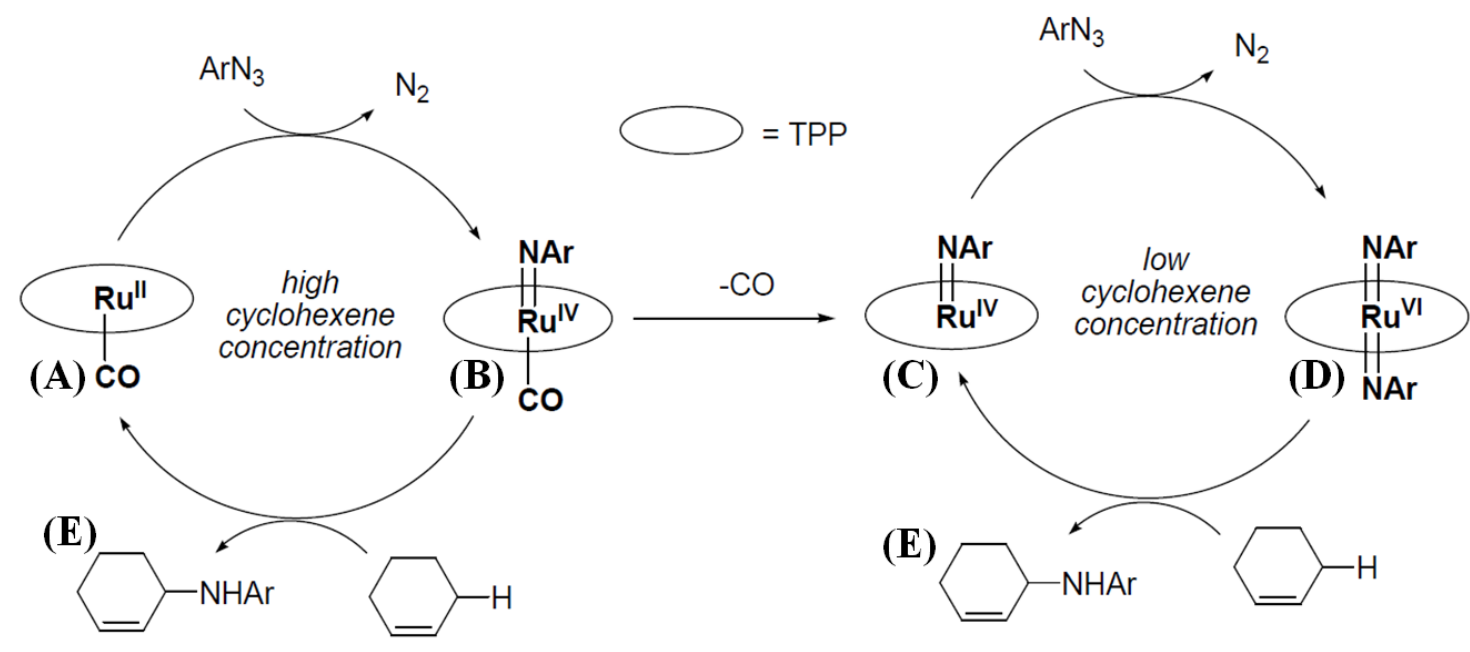

Figure 1 

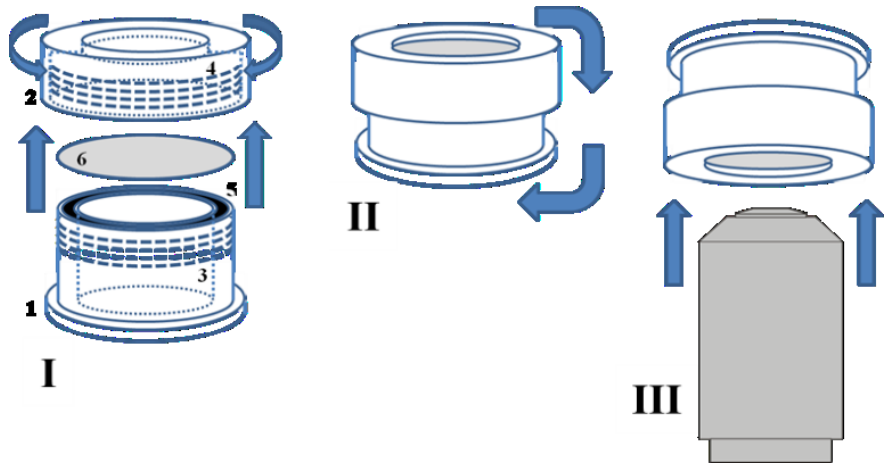

Figure 2 


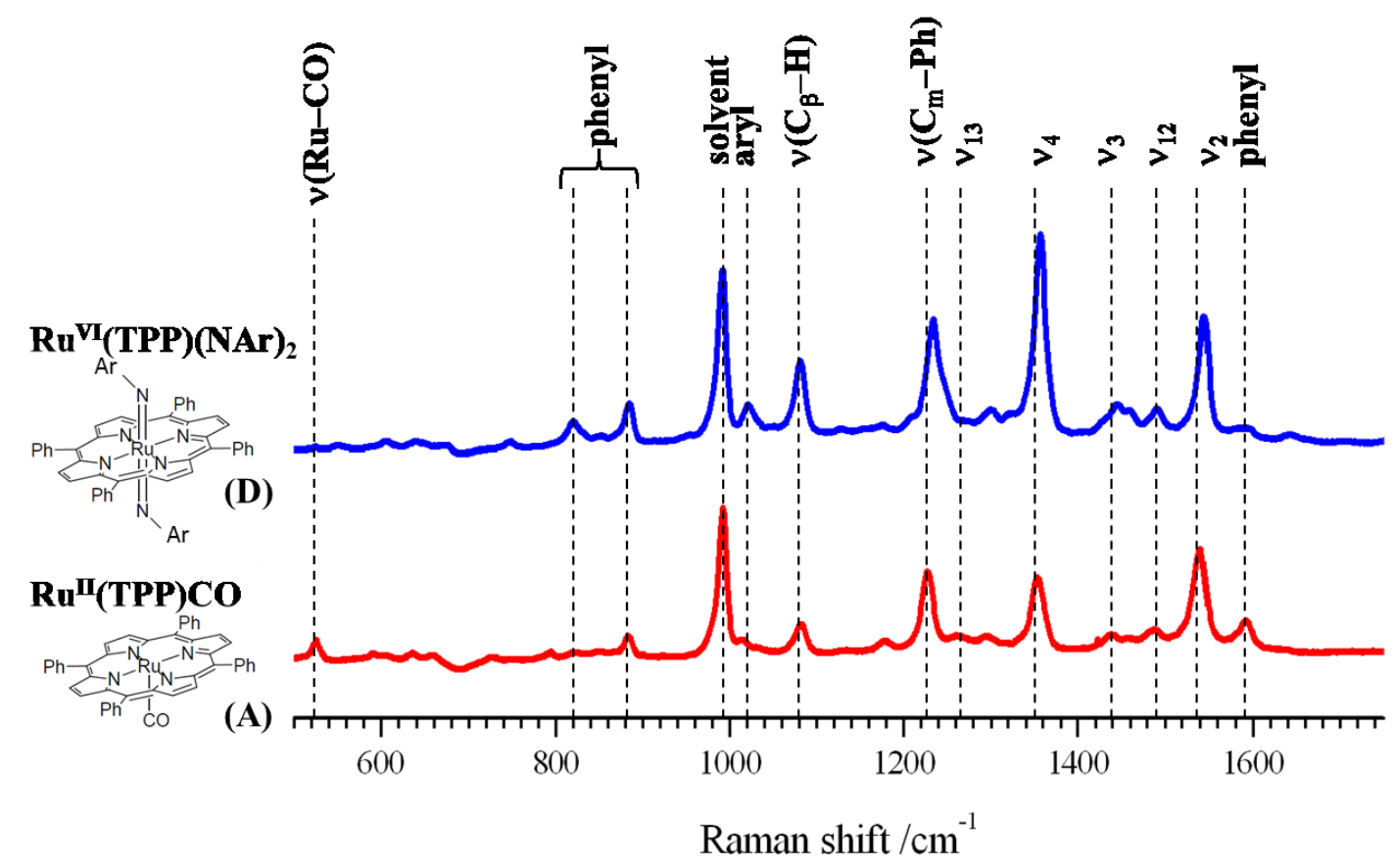

Figure 3 


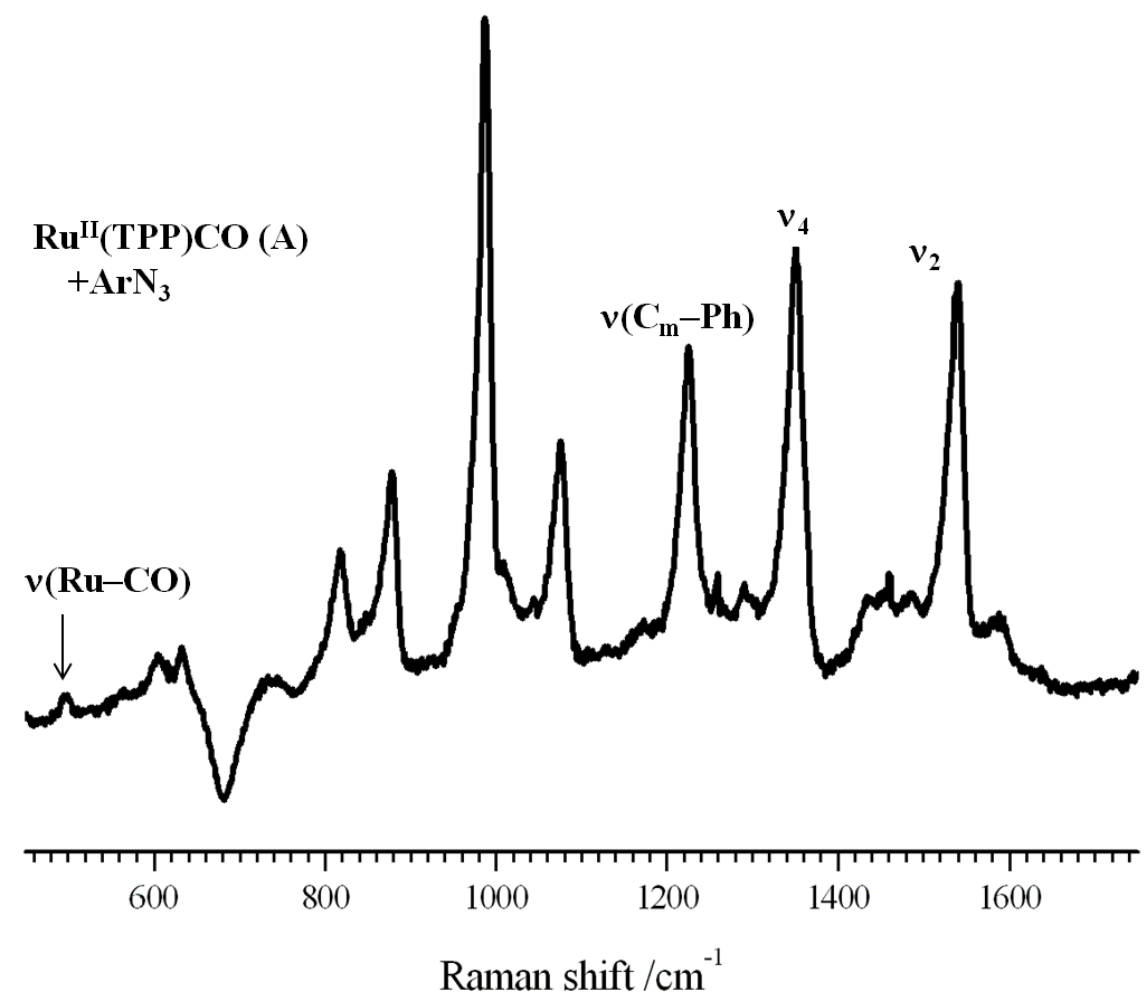

Figure 4 


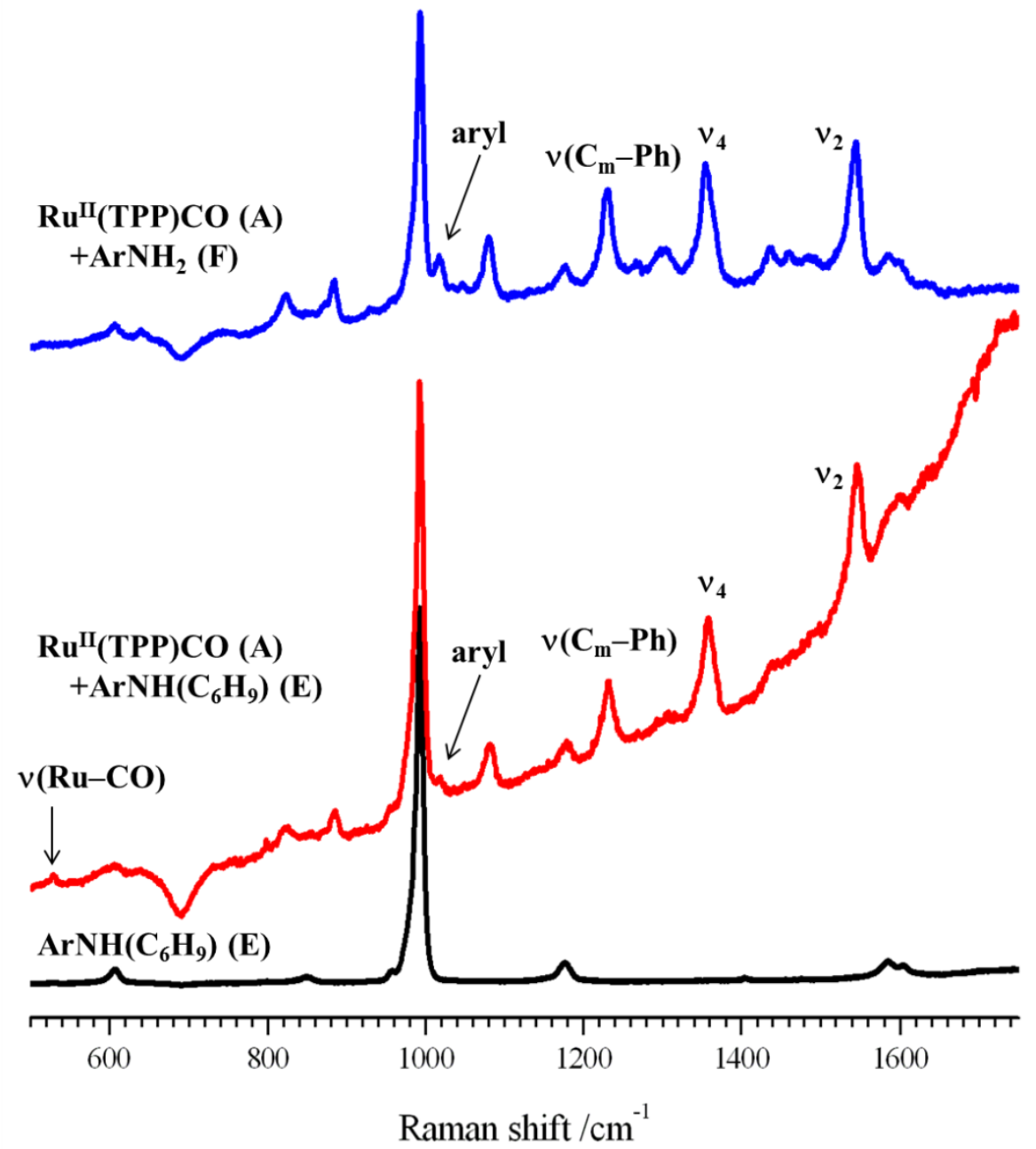

Figure 5 


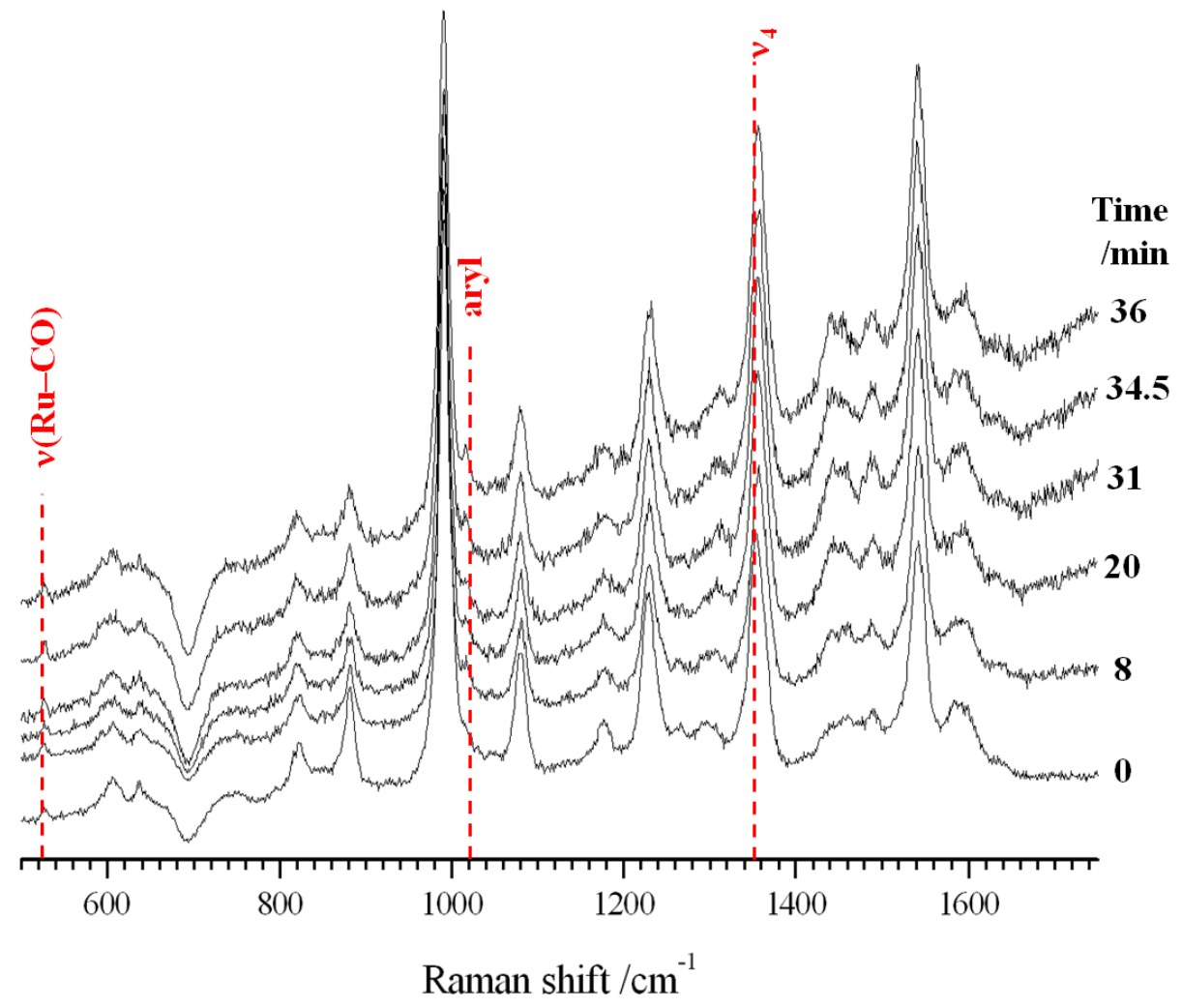

Figure 6 


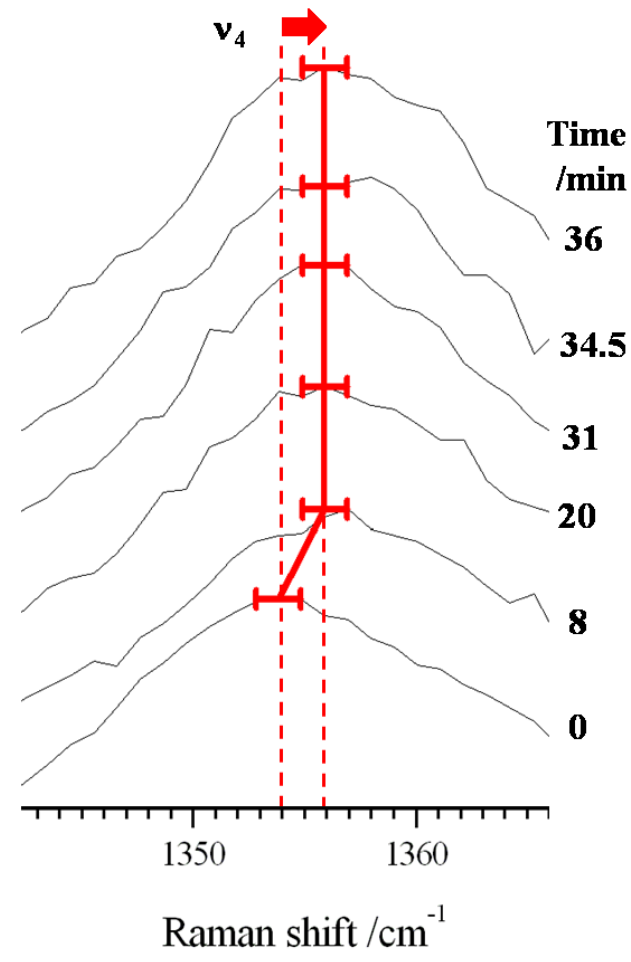

Figure 7 


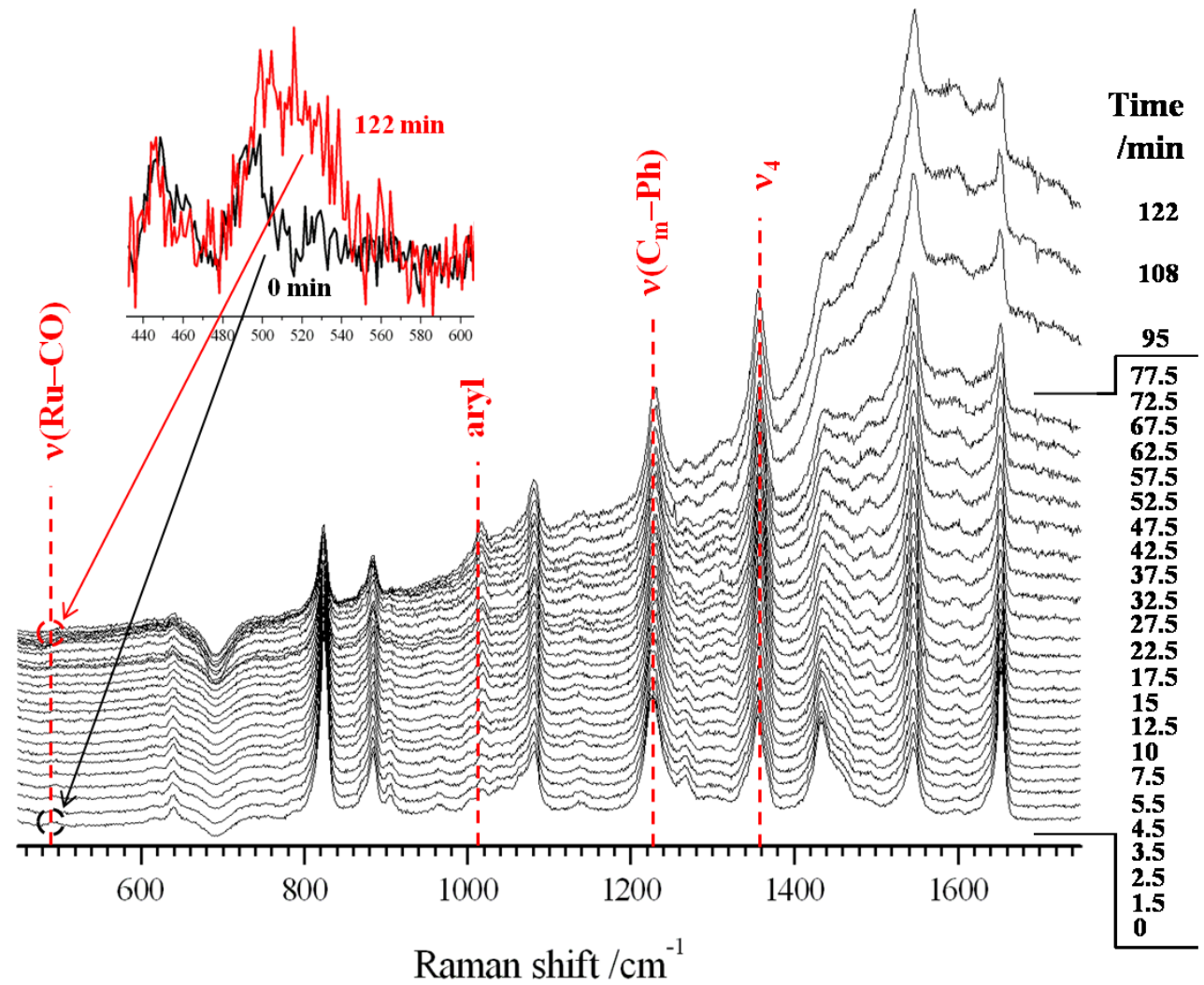

Figure 8 


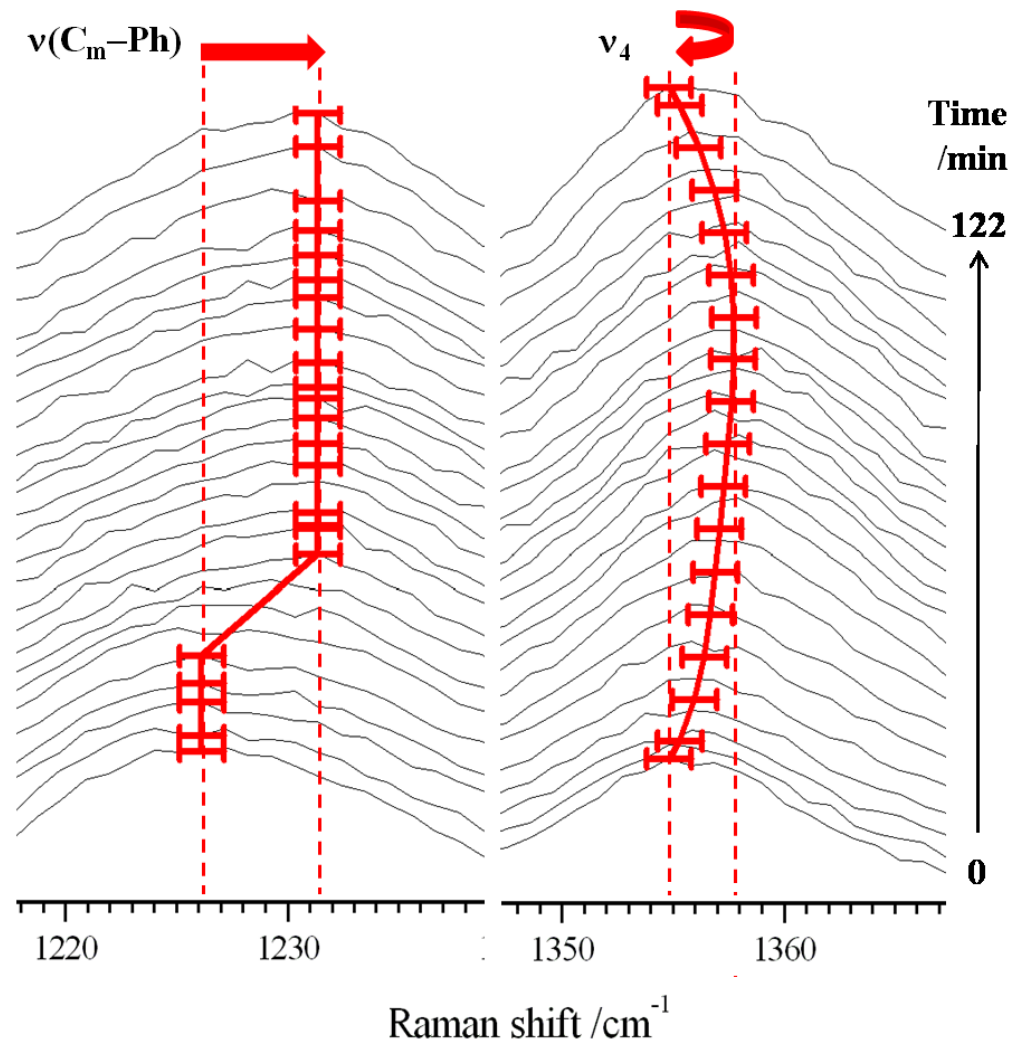

Figure 9 


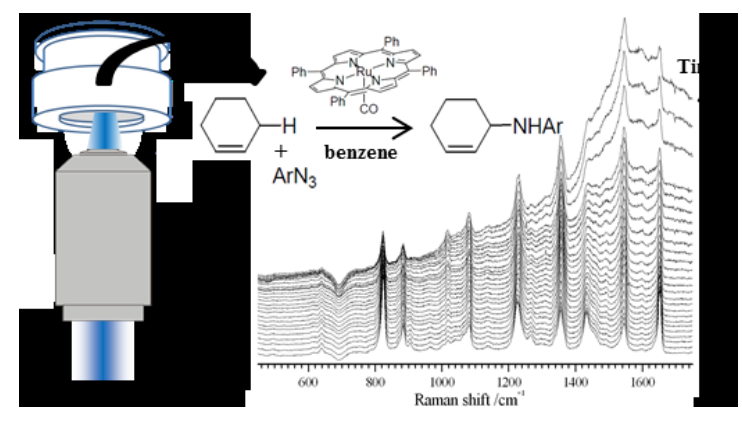

\section{Table of Contents Graphic}

Text: A method to monitor the mechanisms of homogeneously-catalysed reactions under conditions of refluxing solvents using resonance Raman spectroscopy 
${ }^{1}$ J. R. Ferraro and K. Nakamoto, Introductory Raman Spectroscopy, Academic Press: New York, 1994.

${ }^{2}$ P. Pagsberg, R. Wilbrandt, K. B. Hansen and K. V. Weisberg, Chem. Phys. Letts., 1976, 39, 538541.

${ }^{3}$ E. Vauthey, D. Phillips and A. W. Parker, J. Phys. Chem., 1992, 96, 7356-7360.

${ }^{4}$ S. E. J. Bell, Analyst, 1996, 121, R107-R120.

${ }^{5}$ Y. L. Li, K. H. Leung and D. L. Phillips, J. Phys. Chem. A. 2001, 105, 10621-10625.

${ }^{6}$ S. Hu, K. M. Smith and T. G. Spiro J. Am. Chem. Soc. 1996, 118, 12638-12646.

${ }^{7}$ S. Hu, I. K. Morris, J. P. Singh, K. M Smith and T. G. Spiro, J. Am. Chem. Soc. 1993, 115, $12446-$ 12458.

${ }^{8}$ T. G. Spiro and T. C. Strekas, J. Am. Chem. Soc. 1974, 96, 338-345.

${ }^{9}$ K. R. Ward, I. Torres Filho, R. W. Barbee, L. Torres, M. H. Tiba, P. S. Reynolds, R. N. Pittman, R. R. Ivatury and J. Terner, Crit. Care Med. 2006, 34, 792-799.

${ }^{10}$ K. R. Ward, R. W. Barbee, P. S. Reynolds, I. P. Torres Filho, M. H. Tiba, L. Torres, R. N. Pittman and J. Terner, Anal. Chem. 2007, 79, 1514-1518.

${ }^{11}$ A. Almohammedi, S. M. Kapetanaki, B. R. Wood, E. L. Raven, N. M. Storey and A. J. Hudson, J. R. Soc. Interface 2015, 12, 20141339.

${ }^{12}$ K. Grabow and U. Bentrup, ACS Catalysis 2014, 4, 2153-216.

${ }^{13}$ P. W. N. M. Leeuwen, Homogeneous Catalysis: Understanding the Art, Kluwer: Dordrecht, 2004.

${ }^{14}$ S. Bhaduri and D. Mukesh, Homogeneous Catalysis: Mechanisms and Industrial Applications, $2^{\text {nd }}$ Edtn., John Wiley \& Sons: New York 2014.

${ }^{15}$ D. Kim, Y. O. Su and T. G. Spiro, Inorg. Chem. 1986, 25, 3993-3997.

${ }^{16}$ G. D. Danzer, J. A. Golus and J. R. Kincaid, J. Am. Chem. Soc. 1993, 115, 8643-8648.

${ }^{17}$ G. D. Danzer and J. R. Kincaid, J. Phys Chem. 1990, 94, 3976-3980.

${ }^{18}$ D. J. Ma'nuel, D. P. Strommen, A. Bhuiyan, M. Sykora and J. R. Kincaid, J. Raman Spectroscopy 1997, 28, 933-938.

${ }^{19}$ S. Fantauzzi, E. Gallo, A. Caselli, F. Ragaini, N. Casati, P. Macchi and S. Cenini, Chem. Commun. 2009, 3952-3954. 
${ }^{20}$ J. T. Groves and T. Takahashi, J. Am. Chem. Soc. 1983, 105, 2073-2074.

${ }^{21}$ G.-Y. Gao, J. E. Jones, R. Vyas, J. D. Harden and X. P. Zhang, J. Org. Chem. 2006, 71, 6655-6658.

${ }^{22}$ W. Xiao, J. Wei, C.-Y. Zhou and C.-M. Che, Chem. Commun. 2013, 49, 4619-4621.

${ }^{23}$ J. V. Ruppel, J. E. Jones, C. A. Huff, R. M. Kamble, Y. Chen and X. P. Zhang, Org. Lett. 2008, 10, 1995-1998.

${ }^{24}$ Y. Liu and C.-M. Che, Chem. Eur. J. 2010, 16, 10494-10501.

${ }^{25}$ J. P. Mahy, G. Bedi, P. Battioni and D. Mansuy, New J. Chem. 1989, 13, 651-657.

${ }^{26}$ J. P. Mahy, P. Battioni and D. Mansuy, J. Am. Chem. Soc. 1986, 108, 1079-1080.

${ }^{27}$ J.-L. Liang, J.-S. Huang, X.-Q. Yu, N. Zhu and C.-M. Che, Chem. Eur. J. 2002, 8, 1563-1572.

${ }^{28}$ X.-G. Zhou, X.-Q. Yu, J.-S. Huang and C.-M. Che, Chem. Commun. 1999, 2377-2378.

${ }^{29}$ X. Q. Yu, J. S. Huang, X. G. Zhou and C. M. Che, Org. Lett. 2000, 2, 2233-2236.

${ }^{30}$ S.-M. Au, W.-H. Fung, M.-C. Cheng, C.-M. Che and S.-M. Peng, Chem. Commun. 1997, 16551656.

${ }^{31}$ S.-M. Au, J.-S. Huang, W.-Y. Yu, W.-H. Fung and C.-M. Che, J. Am. Chem. Soc. 1999, 121, $9120-$ 9132.

${ }^{32}$ C.-M. Che and W.-Y. Yu, Pure Appl. Chem. 1999, 71, 281-288.

${ }^{33}$ J. P. Mahy, G. Bedi, P. Battioni and D. Mansuy, J. Chem. Soc., Perkin Trans. 2 1988, 1517-1524.

${ }^{34}$ J.-P. Simonato, J. Pecaut, J.-C. Marchon and W. R. Scheidt, Chem. Commun. 1999, 989-990.

${ }^{35}$ J.-L. Liang, S.-X. Yuan, J.-S. Huang, W.-Y. Yu and C.-M. Che, Angew. Chem. Int. Ed. 2002, 41, $3465-3468$.

${ }^{36}$ X. Lin, C.-M. Che and D. L. Phillips, J. Org. Chem. 2008, 73, 529-537.

${ }^{37}$ D. Intrieri, A. Caselli, F. Ragaini, P. Macchi, N. Casati and E. Gallo, Eur. J. Inorg. Chem. 2012, 569-580.

${ }^{38}$ G. Manca, E. Gallo, D. Intrieri and C. Mealli, ACS Catalysis 2014, 4, 723-832.

${ }^{39}$ Z. Guo, X. Guan, J.-S. Huang, W.-M. Tsui, Z. Lin and C.-M. Che, Chem. Eur. J. 2013, 19, 1132011331.

${ }^{40}$ E. Gallo, A. Caselli, F. Ragaini, S. Fantauzzi, N. Masciocchi, A. Sironi and S. Cenini, Inorg. Chem. 2005, 44, 2039-2049.

${ }^{41}$ M. Tanno, S. Sueyoshi and S. Kamiya, Chem. Pharm. Bull. 1982, 30, 3125-3132. 